\title{
(6) OPEN ACCESS \\ REM sleep behaviour disorder is associated with worse quality of life and other non-motor features in early Parkinson's disease
}

- Additional material is published online only. To view please visit the journal online (http://dx.doi.org/10.1136/ jnnp-2013-306104)

${ }^{1}$ Department of Physiology, Anatomy and Genetics, Oxford Parkinson's Disease Centre, Oxford, UK

${ }^{2}$ Nuffield Department of Clinical Neurosciences, Division of Neurology, University of Oxford, Oxford, UK

${ }^{3}$ Department of Clinical Neurology, John Radcliffe Hospital, Oxford, UK ${ }^{4}$ School of Social and Community Medicine, University of Bristol, Bristol, UK

Correspondence to Dr Michele Hu, Nuffield Department of Clinical Neurosciences, Level 3, West Wing, John Radcliffe Hospital, Headley Way, Headington, Oxford OX3 9DE, UK michele.hu@ndcn.ox.ac.uk

Received 13 June 2013 Revised 30 September 2013 Accepted 7 October 2013 Published Online First 1 November 2013

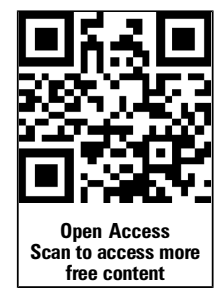

To cite: Rolinski $\mathrm{M}_{\text {, }}$ Szewczyk-Krolikowski K, Tomlinson PR, et al. J Neurol Neurosurg Psychiatry 2014;85:560-566.

\author{
Michal Rolinski, ${ }^{1,2}$ Konrad Szewczyk-Krolikowski, ${ }^{1,2}$ Paul R Tomlinson, ${ }^{1,2}$ \\ Kannan Nithi, ${ }^{1,3}$ Kevin Talbot, ${ }^{1,3}$ Yoav Ben-Shlomo, ${ }^{1,4}$ Michele TM Hu ${ }^{1-3}$
}

\section{ABSTRACT \\ Background Concomitant REM sleep behaviour} disorder (RBD) is commonly observed in patients with Parkinson's disease (PD). Although the brainstem structures responsible for the symptoms of RBD correspond to the premotor stages of $\mathrm{PD}$, the association of RBD with motor and non-motor features in early PD remains unclear.

Methods The study evaluated 475 patients with PD within 3.5 years of diagnosis for the presence of probable RBD ( $p R B D$ ) using the REM Sleep Behaviour Disorder Screening Questionnaire (RBDSQ). A neurologist and a trained research nurse carried out evaluation of each participant blinded to the results of the RBDSQ. Standardised rating scales for motor and non-motor features of PD, as well as health-related quality of life measures, were assessed. Multiple linear and logistic regression analyses were used to determine the relationship between $\mathrm{pRBD}$ and a variety of outcomes, controlling for confounding factors.

Results The overall frequency of pRBD was $47.2 \%$ (95\% Cl $42.7 \%$ to $51.9 \%$ ). None of the patients had a previous diagnosis of RBD. Patients with PD and concomitant PRBD did not differ on motor phenotype and scored comparably on the objective motor scales, but reported problems with motor aspects of daily living more frequently. Adjusted for age, sex, disease duration and smoking history, pRBD was associated with greater sleepiness $(p=0.001)$, depression $(p=0.001)$ and cognitive impairment $(p=0.006)$.

Conclusions pRBD is common and under-recognised in early PD. It is associated with increased severity and frequency of non-motor features, poorer subjective motor performance and a greater impact on health-related quality of life.

\section{INTRODUCTION}

REM sleep behaviour disorder (RBD), first described by Schenck and colleagues in $1986,{ }^{1}$ is characterised by the loss of normal muscle atonia during REM sleep. Patients often experience violent dream-enacting behaviours leading to disturbed sleep and potential injuries to themselves and their bed partner. While polysomnography (PSG) remains the diagnostic gold standard, the diagnosis of probable RBD (pRBD) can be made based on clinical judgment or validated questionnaires. ${ }^{2}$ Although human pathophysiological data are somewhat limited, our current understanding suggests that it is the loss of nuclei in the tegmentum pontis and the medial medulla oblongata which are responsible for the symptoms of RBD. $^{3}$

Over the past 20 years, a number of key studies have linked the presence of idiopathic RBD with a future increased risk of developing neurodegenerative disease, including parkinsonism and dementia. $^{4-6}$ Recently, Schenck and colleagues reported that over $80 \%$ of males aged 50 years and older initially diagnosed with idiopathic RBD developed a neurodegenerative disorder, with the vast majority being diagnosed with Parkinson's disease (PD). ${ }^{7}$ These findings question the existence of 'idiopathic' $\mathrm{RBD}$, which more likely represents the early presentation of other neurodegenerative disorders. It is therefore unsurprising that the symptoms of RBD have been reported in up to $60 \%$ of patients with PD. ${ }^{8}$

A number of groups have studied the association between RBD and PD phenotypes (reviewed by Arnulf ${ }^{9}$ ). These suggest that patients with concomitant RBD are more likely to have a non-tremor phenotype, have a poor response to medication and suffer from more non-motor symptoms. However, most of these observations were based on a small number of patients with relatively prolonged disease duration. As brainstem structures responsible for the symptoms of RBD correspond to stage 2 of the Braak pathophysiological classification of $\mathrm{PD},{ }^{3}{ }^{10}$ we hypothesise that the symptoms of RBD occur early in the natural history and may be associated with a different clinical phenotype. In this study, we have endeavoured to estimate the prevalence and describe the association between pRBD and motor and non-motor features in a large cohort of subjects with early PD.

\section{METHODS}

\section{Patient selection}

A consecutive sample of early PD patients (time from diagnosis $\leq 3.5$ years) was prospectively recruited as part of the Oxford Parkinson's Disease Centre (OPDC) cohort study (PD-Discovery) from 10 hospitals across the Thames Valley covering an estimated population of 2.9 million. Participants were recruited between September 2010 and August 2012. Patients were eligible for study inclusion if they met the UK Parkinson's Disease Society Brain bank criteria ${ }^{11}$ for the diagnosis of idiopathic Parkinson's disease, as judged by a neurologist. Patients with secondary parkinsonism due to head 
trauma or medication use, or features of atypical parkinsonism syndromes, such as multiple system atrophy, progressive supranuclear palsy, corticobasal degeneration or dementia with Lewy bodies, were excluded.

The study was undertaken with the understanding and written consent of each subject, with the approval of the local NHS ethics committee, and in compliance with national legislation and the Declaration of Helsinki.

\section{RBD screening questionnaire}

Participants were asked to complete the REM Sleep Behaviour Disorder Screening Questionnaire (RBDSQ) ${ }^{12}$ prior to attending the study clinic. The RBDSQ is a patient self-rating instrument with ten questions (yes/no) assessing various aspects of sleep behaviour. The input of the patient's bed partner is encouraged but is not necessary. Questions 1 to 4 assess the content and frequency of dreams and their relationship to nocturnal movements and behaviour; question 5 asks about potential nocturnal injuries sustained by the patient or their bed partner; question 6 is divided into four subsections and is designed to assess nocturnal motor behaviour, for example, vocalisation, sudden limb movements, complex movements or bedding items that fall down; questions 7 and 8 deal with nocturnal awakenings; question 9, with disturbed sleep in general; and, question 10, with the presence of any neurological disorder. The maximum total score of the RBDSQ is 13, with a higher score suggesting more features associated with RBD. A cut-off score of 5 was reported by the authors as most useful when differentiating patients with idiopathic RBD from controls. ${ }^{12}$ As this cut-off is only associated with a specificity of $0.56,{ }^{12}$ sensitivity analyses were also performed using a RBDSQ cut-off of 6 and 7, in the light of subsequent validation studies that found stronger test performance characteristics using these higher cut-offs. ${ }^{13} 14$

\section{Patient evaluation}

A study neurologist and a trained research nurse carried out comprehensive evaluation of each patient blinded to the results of the RBDSQ.

The following measures of interest were included:

1. Patient demographics, including age, sex and smoking history. A comprehensive past medical history was taken. Disease duration was calculated from the date the diagnosis was made. The delay to diagnosis was defined as the number of months between the onset of motor symptoms and the date of diagnosis. As the date of symptom onset was based on participant relocation and thus opens to bias, only disease duration was included in further analyses. A detailed history of all medication use was taken from the patients and, where available, medication records were reviewed. For dopaminergic medications, the levodopa equivalent daily dose (LEDD) was calculated. The response to PD medications was assessed using the patient-rated Clinical Global Impression of Change (CGIC) Scale. Concomitant use of medications associated with symptoms of RBD was recorded (antidepressants and bisoprolol ${ }^{15}$ ). Where available, clinic letters were reviewed for the presence of resting tremor, rigidity, bradykinesia and postural instability at the time of first presentation.

2. Motor features of PD, including parts II, III and IV of the Movement Disorders Society (MDS) revised Unified Parkinson's Disease Rating Scale (UPDRS). ${ }^{16}$ Tremor and postural instability/gait disorder (PIGD) scores were calculated as the sum of all tremor (maximum subscore of 36) and postural instability and gait disorder (maximum subscore of 8 ) scorings on UPDRS III. ${ }^{17}$ Hand dexterity, motor speed and coordination were assessed using the Purdue Pegboard Test; the total number of pegs inserted using each hand individually and then both hands over a total of $90 \mathrm{~s}$, and the total number of components assembled during the $60 \mathrm{~s}$ assembly task were used as the outcome measures. The Timed Up \& Go (the average time over three attempts to get up from sitting and walk $3 \mathrm{~m}$ ) and the Flamingo tests (testing the ability of the patient to balance on one leg for $30 \mathrm{~s})$ were also performed to assess gait and postural stability. All motor assessments were performed while the subject was taking their usual PD medications in a clinically defined 'on' state.

3. Non-motor features of PD, including UPDRS I. Daytime sleepiness was assessed using the Epworth Sleepiness Scale (ESS). Olfaction was assessed using the 'Sniffin' Sticks' odour identification test. Participants were presented with 16 felt-tip pens scented with 16 common odours and asked to identify each one from a choice of four (maximum score of 16). Cognition was assessed using the Mini-Mental State Examination (MMSE) and the Montreal Cognitive Assessment (MoCA). Scores on both tests were normalised for years of education (calculated as the number of years at school plus years of further education). Cognitive impairment was defined according to the MMSE and MoCA screening cut-offs $(<26 / 30) .{ }^{18}$ For phonemic and semantic fluency, the total number of words generated beginning with F, A and S, and animal and boys' names category, respectively, over $60 \mathrm{~s}$ each was counted. The Beck Depression Inventory was used to evaluate depression. ${ }^{19}$ The Questionnaire for Impulsive-Compulsive Disorders in Parkinson's Disease (QUIP, Anytime Short) ${ }^{20}$ was used to test for impulse control disorders (gambling, sexual, buying and eating behaviours) and compulsive behaviours (punding, hobbyism and walkabout (excessive, aimless wandering)). A postural drop in blood pressure was defined as the difference in the systolic blood pressure measured with the patient lying on the examination couch for $3 \mathrm{~min}$ and again $2 \mathrm{~min}$ after standing. In relation to constipation, participants were asked about their bowel frequency and laxative use.

4. Health-related quality of life was assessed using the EQ-5D questionnaire, ${ }^{21}$ with patients asked to assess their quality of life according to five domains (mobility, self-care, activities, pain and anxiety), as well as scoring their health out of 100 on a visual analogue scale.

\section{Statistical analysis}

Analysis of descriptive variables was performed using two-tailed unpaired $\mathrm{t}$ tests and $\chi^{2}$ tests for continuous and ordinal variables, respectively. Multivariable linear and logistic regression analyses were used to determine the independent relationship between pRBD and the dependent variable, controlling for age, sex, disease duration and smoking history (number of packyears, where one pack-year equates to smoking 20 cigarettes per day for 1 year). We have presented the crude results (means and percentages) and the adjusted difference in means and ORs (95\% CIs and $\mathrm{p}$ values) for continuous and binary variables, respectively. The total years of education was also used as a covariate when comparing the MMSE and MoCA. Cut-off for statistical significance was defined as $p<0.05$. No formal adjustment was made for multiple testing but $\mathrm{p}$ values between 0.01 and 0.05 were treated with caution, unless previously reported, given the possibility of type I errors. 


\section{RESULTS}

A total of 481 individuals participated in the study. Six subjects were excluded due to an incomplete RBDSQ, leaving 475 for analysis, of whom 292 were male (61.5\%). The mean (SD) age was 67.7 (9.5) years and mean (SD) disease duration was 1.5 (1.0) years. According to patient reports, none of the participants had previously been given the diagnosis, either clinical or PSG-confirmed, of RBD. Only four participants were on medications used to treat the symptoms of RBD (one participant was receiving melatonin and three were on clonazepam). A total of 224 subjects with PD $(47.2 \%, 95 \%$ CI $42.7 \%$ to $51.9 \%)$ were identified to have a diagnosis of pRBD using the RBDSQ at the recommended cut-off score of five. One hundred and seventy six $(37.1 \%, 95 \%$ CI $32.8 \%$ to $41.7 \%)$ and $141(29.7 \%, 95 \%$ CI $25.6 \%$ to $33.4 \%$ ) subjects were diagnosed with concomitant pRBD using a RBDSQ cut-off of six and seven, respectively. The results using a RBDSQ cut-off of five are described herein.

\section{Basic demographics}

Table 1 shows the demographics and medication details of the PD-non-RBD and PD-RBD groups. Both groups had similar ages, disease duration and duration of symptoms prior to the formal diagnosis of PD being made. The PD-RBD group was more likely to be male, although there was only weak evidence against the null hypothesis $(\mathrm{p}=0.05)$. The use of PD medications did not differ between the two groups, with no difference between the numbers of patients on levodopa or dopamine agonists. While LEDD was the same in both groups, subjects with pRBD were more likely to report benefit from their PD medications on the CGIS $(77.6 \%$ vs $85.6 \%, p=0.03)$. Both use of medications previously associated with symptoms of RBD and smoking was more common in the PD-RBD group. The presence of resting tremor, rigidity, bradykinesia and postural instability at the time of diagnosis was comparable in the two groups (clinic letters from the time of diagnosis were available for 337 of the 475 participants (70.9\%)).

\section{Severity of motor symptoms}

There was no statistically significant difference in the quantitative motor measures between patients with $\mathrm{PD}$ with and without pRBD (table 2). The total UPDRS III motor score was

Table 1 Demographic and medication data in subjects with Parkinson's disease (PD-non-RBD) and Parkinson's disease and probable REM sleep behaviour disorder (PD-RBD)

\begin{tabular}{|c|c|c|c|c|}
\hline & & $\begin{array}{l}\text { PD-non-RBD } \\
(\mathrm{n}=251)\end{array}$ & $\begin{array}{l}\text { PD-RBD } \\
(n=224)\end{array}$ & p Value \\
\hline \multicolumn{2}{|l|}{ Age, years } & $67.9 \pm 9.5$ & $67.5 \pm 9.4$ & 0.6 \\
\hline \multicolumn{2}{|l|}{ Sex, \% male } & 57.4 & 66.1 & 0.05 \\
\hline \multicolumn{2}{|c|}{ Disease duration, years } & $1.4 \pm 1.0$ & $1.6 \pm 1.0$ & 0.14 \\
\hline \multicolumn{2}{|c|}{ Delay to diagnosis, years } & $1.7 \pm 1.7$ & $1.6 \pm 1.7$ & 0.8 \\
\hline $\begin{array}{l}\text { Taking PD } \\
\text { medications }\end{array}$ & $\begin{array}{l}\text { Any, \% } \\
\text { Levodopa, \% } \\
\text { Dopamine } \\
\text { agonist, \% } \\
\text { LEDD, mg/d }\end{array}$ & $\begin{array}{l}90.0 \\
51.0 \\
40.6\end{array}$ & $\begin{array}{l}93.8 \\
58.0 \\
38.8\end{array}$ & $\begin{array}{l}0.14 \\
0.12 \\
0.7\end{array}$ \\
\hline \multicolumn{2}{|c|}{$\begin{array}{l}\text { Patients reporting improvement } \\
\text { on medication, \% }\end{array}$} & 77.6 & 85.6 & 0.03 \\
\hline \multicolumn{2}{|c|}{$\begin{array}{l}\text { Taking medications associated } \\
\text { with symptoms of RBD, \% }\end{array}$} & 12.7 & 21.4 & 0.01 \\
\hline \multicolumn{2}{|c|}{ Smoking history, \% } & 34.3 & 44.8 & 0.02 \\
\hline
\end{tabular}

the same in the two groups, as was the total tremor and PIGD score, and Hoehn and Yahr stage. Participants with pRBD performed similarly well on the Purdue Pegboard, Timed Up and Go and Flamingo tests. There was no difference in the frequency of reported dyskinesia or motor fluctuations. Participants with pRBD more frequently reported problems with every motor aspect of experience of daily living included in UPDRS II (score $>0$ ), with problems with speech, chewing and swallowing, turning in bed, and walking and balance reaching statistical significance. Freezing was reported more than two times more commonly by subjects with concomitant pRBD $(p<0.001)$, but no difference in gait freezing was observed as part of UPDRS III PD-non-RBD 7/251 vs PD-RBD 9/224, $p=0.5$ )

\section{Non-motor symptoms}

Participants with pRBD scored significantly higher on ESS, reported fewer bowel motions per day and had a larger drop in systolic blood pressure on standing from a lying position (table 3 ). Although subjects without pRBD tended to score higher on the Sniffin Smell Test, this was consistent with chance $(p=0.07)$. Higher depression scores were seen using the Beck Depression Inventory in the pRBD group. A statistically significant difference in baseline cognition was evident on the MMSE $(p=0.03)$, but not the MoCA $(p=0.2)$, with no evident difference in phonemic and semantic fluency. There was no difference in the frequency of impulsive-compulsive disorders in the two groups.

Patients with concomitant PD and pRBD had a poorer outcome in almost every non-motor domain of UPDRS I. Patients with $\mathrm{pRBD}$ reported a statistically significant increase in the frequency of cognitive impairment, hallucinations, depressed and anxious mood, and apathy. Moreover, they suffered more pain, urinary problems, constipation and light-headedness on standing.

\section{Health-related quality of life}

Participants with concomitant probable RBD more commonly reported impairment in each domain of the EQ-5D and reported a lower health score overall (table 4).

\section{Sensitivity analyses}

We repeated all the main analyses using the higher RBDSQ cut-off points of 6 and 7 and found the pattern of results to be qualitatively similar. Using a cut-off of 6 , a significant difference between the two groups could now be observed in the MoCA score $(24.8 \pm 3.5$ vs $24.0 \pm 3.7, p=0.034)$, and the per cent of participants reporting daytime sleepiness and fatigue on UPDRS I (77.8\% vs $86.0 \%, \mathrm{p}=0.035$ and $69.0 \%$ vs $79.2 \%, \mathrm{p}=0.023$ respectively). Conversely, any differences in the number of participants reporting urinary problems on UPDRS I $(p=0.073)$, speech problems on UPDRS II $(p=0.1),<1$ bowel motion per day $(p=0.1)$ and mobility problems on the EQ-5D questionnaire $(p=0.1)$ could now be attributed to chance. Using a cut-off of 7 , the null hypothesis could not be rejected when comparing the percentage of participants with a smoking history $(p=0.15)$ or reporting $<1$ bowel motion per day $(\mathrm{p}=0.3)$ or pain and urinary problems on UPDRS I ( $p=0.06$ and 0.1 , respectively), in the two groups. This was also the case for participants reporting speech or walking and balance problems on UPDRS II $(p=0.08$ and $p=0.3$, respectively), or mobility problems on EQ-5D $(p=0.3)$. Interestingly, when using a cut-off of 7 , participants with pRBD were more likely to report punding behaviour on QUIP $(4.0 \%$ vs $10.0 \%, \mathrm{p}=0.02$ ) and symptoms of dopamine dysregulation syndrome on UPDRS I $(2.4 \%$ vs $7.8 \%, \mathrm{p}=0.01)$. 
Table 2 Motor symptoms in subjects with Parkinson's disease (PD-non-RBD) and Parkinson's disease and probable REM sleep behaviour disorder (PD-RBD)

\begin{tabular}{|c|c|c|c|c|c|}
\hline & & PD-non-RBD $(n=251)$ & PD-RBD $(n=224)$ & $\begin{array}{l}\text { Adjusted difference in means* } \\
\text { (PD-RBD-PD-non-RBD) }(95 \% \mathrm{CI})\end{array}$ & p Value* \\
\hline \multicolumn{6}{|l|}{ Continuous measures } \\
\hline UPDRS III & $\begin{array}{l}\text { Total } \\
\text { Tremor score } \\
\text { PIGD score } \\
\text { Hoehn \& Yahr }\end{array}$ & $\begin{array}{c}26.9 \pm 11.2 \\
3.3 \pm 2.4 \\
1.2 \pm 1.2 \\
1.9 \pm 0.5\end{array}$ & $\begin{array}{c}26.8 \pm 10.6 \\
3.4 \pm 2.8 \\
1.3 \pm 1.3 \\
1.9 \pm 0.5\end{array}$ & $\begin{array}{r}-0.12(-2.08 \text { to } 1.84) \\
0.03(-0.44 \text { to } 0.50) \\
0.17(-0.05 \text { to } 0.39) \\
0.15(-0.26 \text { to } 0.56)\end{array}$ & $\begin{array}{l}0.9 \\
0.9 \\
0.14 \\
0.5\end{array}$ \\
\hline Purdue Pegboard, s & $\begin{array}{l}\text { Total } \\
\text { Assembly }\end{array}$ & $\begin{array}{l}28.7 \pm 6.9 \\
17.0 \pm 6.2\end{array}$ & $\begin{array}{l}28.0 \pm 6.9 \\
17.0 \pm 6.1\end{array}$ & $\begin{array}{r}-0.57(-1.72 \text { to } 0.59) \\
0.07(-0.97 \text { to } 1.11)\end{array}$ & $\begin{array}{l}0.3 \\
0.9\end{array}$ \\
\hline Timed Up and Go, s & & $10.0 \pm 4.5$ & $10.6 \pm 4.9$ & $0.79(-0.05$ to 0.63$)$ & 0.07 \\
\hline Binary measures & & & & Adjusted OR* $(95 \% \mathrm{Cl})$ & \\
\hline UPDRS IV, \% & $\begin{array}{l}\text { Dyskinesia } \\
\text { Motor fluctuations }\end{array}$ & $\begin{array}{l}0.05 \\
0.04\end{array}$ & $\begin{array}{l}0.05 \\
0.03\end{array}$ & $\begin{array}{l}0.89(0.38 \text { to } 2.02) \\
0.68(0.24 \text { to } 1.97)\end{array}$ & $\begin{array}{l}0.8 \\
0.5\end{array}$ \\
\hline UPDRS II, \% & $\begin{array}{l}\text { Speech } \\
\text { Saliva and drooling } \\
\text { Chewing and swallowing } \\
\text { Eating tasks } \\
\text { Dressing } \\
\text { Hygiene } \\
\text { Handwriting } \\
\text { Doing hobbies and other activities } \\
\text { Turning in bed } \\
\text { Tremor } \\
\text { Getting out of bed } \\
\text { Walking and balance } \\
\text { Freezing }\end{array}$ & $\begin{array}{l}32.1 \\
46.4 \\
16.8 \\
46.4 \\
54.8 \\
35.6 \\
60.0 \\
59.2 \\
47.2 \\
79.6 \\
65.2 \\
59.6 \\
10.4\end{array}$ & $\begin{array}{l}45.7 \\
55.0 \\
38.1 \\
46.6 \\
64.3 \\
44.3 \\
63.3 \\
63.8 \\
60.6 \\
80.5 \\
72.4 \\
69.5 \\
23.5\end{array}$ & $\begin{array}{l}1.52 \text { (1.03 to } 2.25) \\
1.30 \text { (0.89 to } 1.88) \\
1.80(1.45 \text { to } 2.83) \\
0.98 \text { (0.68 to } 1.42) \\
1.42(0.98 \text { to } 2.06) \\
1.39 \text { (0.96 to } 2.02) \\
1.05 \text { (0.71 to } 1.56) \\
1.14 \text { (0.78 to } 1.65) \\
1.77(1.22 \text { to } 2.57) \\
1.05(0.66 \text { to } 1.68) \\
1.40(0.93 \text { to } 2.12) \\
1.48(1.00 \text { to } 2.19) \\
2.64(1.65 \text { to } 4.22)\end{array}$ & $\begin{array}{l}0.03 \\
0.16 \\
0.01 \\
0.9 \\
0.07 \\
0.09 \\
0.8 \\
0.5 \\
0.003 \\
0.8 \\
0.1 \\
0.05 \\
<0.001\end{array}$ \\
\hline Flamingo, \% & & 45.7 & 42.9 & $0.80(0.53$ to 1.21$)$ & 0.3 \\
\hline
\end{tabular}

\section{Post hoc analysis}

We performed a post hoc analysis to exclude cases where the symptoms of RBD could have been attributed to medication use. Eighty of the initial 475 participants (16.8\%) were found to have current or historical use of medications previously associated with symptoms of RBD and were therefore excluded from further analyses. Exclusion of these participants had very little effect on the results described above (see online supplementary tables S1-S4).

\section{DISCUSSION}

To our knowledge, this is the largest comprehensive study of patients with early PD with and without pRBD. We have found that $\mathrm{pRBD}$ is very common in PD, and it is associated with more profound non-motor symptoms, even in the early stages of the disease.

In our study, the frequency of probable RBD was $47.2 \%$, which is similar to that found in more advanced PD (table 5). In line with previously published studies, we have shown that participants with and without probable RBD were of a similar age, ${ }^{22-25}$ sex $^{22-2426}$ and had a similar disease duration. ${ }^{23} 27 \mathrm{We}$ also observed that the delay to diagnosis from the time the patient first noticed any motor symptoms was the same in both groups, suggesting that these patients do not have a significantly more rapid progression of their motor symptoms leading to a quicker diagnosis. This finding supports that of Lavault and colleagues ${ }^{8}$ who found no specific worsening of motor disability scores after a period of follow-up in patients with RBD, when compared to those without.

We found that patients with pRBD were as likely to be on PD medications and had a comparable LEDD, but, somewhat surprisingly, were more likely to report an improvement on their medications $(p=0.03)$ when compared to patients without RBD. If true, this finding would be in direct contrast to previous reports showing a higher levodopa dose and lower levodopa sensitivity in patients with RBD. ${ }^{17}{ }^{24}$ However, as we did not observe a difference in objective motor disability scores, such as UPDRS III, Hoehn and Yahr and the Purdue Pegboard, despite patients with RBD reporting more problems with some motor tasks, such as walking and balance, turning in bed and freezing, it is possible that this finding represents a type I error due to multiple comparisons.

The presence of RBD has previously been associated with non-tremor-dominant phenotype of PD. ${ }^{24}{ }^{34}$ In this study, we have shown that there was no difference in the tremor and PIGD scores at the time the patients were examined, and there was also no difference in the presence of the core signs of parkinsonism at the time the diagnosis was first made. Given the relatively early clinical stage of the participants included in this study, it is possible that the different motor phenotypes are yet to develop. Longitudinal follow-up will assess whether patients' signs will progress at different rates and thus result in a more non-tremor-dominant phenotype over time.

Unlike the motor scores, the non-motor scores were comprehensively worse in the PD-RBD group. We have replicated the findings of previous studies, which have demonstrated an association between RBD and increased frequency of hallucinations, ${ }^{17} 23253035$ daytime sleepiness, ${ }^{23} 31$ constipation $^{31}$ and orthostatic hypotension, ${ }^{28} 36$ and confirmed that it exists in early PD. Contrary to some previous reports, 8222325 we were able to demonstrate a greater prevalence of depression in patients with pRBD when compared to those without, using clinical rating scales and patient reporting. These other negative studies may have been underpowered to demonstrate an 
Table 3 Non-motor symptoms in subjects with Parkinson's disease (PD-non-RBD) and Parkinson's disease and probable REM sleep behaviour disorder (PD-RBD)

\begin{tabular}{|c|c|c|c|c|c|}
\hline & & PD-non-RBD (n=251) & PD-RBD $(n=224)$ & $\begin{array}{l}\text { Adjusted difference in means* } \\
\text { (PD-RBD-PD-non-RBD) }(95 \% \mathrm{Cl})\end{array}$ & p Value* \\
\hline \multicolumn{6}{|c|}{ Continuous measures } \\
\hline \multicolumn{2}{|c|}{ Sniffin Smell Test } & $7.5 \pm 3.0$ & $7.0 \pm 2.9$ & $-0.51(-1.06$ to 0.04$)$ & 0.07 \\
\hline \multicolumn{2}{|c|}{ Orthostatic systolic BP drop, mm Hg } & $4.7 \pm 16.4$ & $9.3 \pm 16.7$ & 4.58 (1.60 to 7.56$)$ & 0.003 \\
\hline \multicolumn{2}{|c|}{ Beck Depression Inventory } & $8.1 \pm 5.5$ & $10.9 \pm 7.3$ & 2.84 (1.61 to 4.07$)$ & $<0.001$ \\
\hline \multicolumn{2}{|c|}{ MMSE } & $27.5 \pm 2.1$ & $27.1 \pm 2.4$ & $-0.44(-0.83$ to -0.05$) \dagger$ & $0.03 t$ \\
\hline \multicolumn{2}{|l|}{ MoCA } & $24.8 \pm 3.5$ & $24.2 \pm 3.7$ & $-0.42(-1.05$ to 0.21$) \dagger$ & $0.2 \dagger$ \\
\hline Fluency & $\begin{array}{l}\text { Phonemic } \\
\text { Semantic }\end{array}$ & $\begin{array}{l}38.8 \pm 14.0 \\
35.4 \pm 9.1\end{array}$ & $\begin{array}{l}38.7 \pm 14.1 \\
34.1 \pm 9.2\end{array}$ & $\begin{array}{r}0.02(-2.51 \text { to } 2.55) \\
-1.16(-2.71 \text { to } 0.39)\end{array}$ & $\begin{array}{l}1.0 \\
0.14\end{array}$ \\
\hline \multicolumn{3}{|c|}{ Binary measures } & & Adjusted OR* $(95 \% \mathrm{Cl})$ & \\
\hline \multicolumn{2}{|c|}{ Epworth Sleepiness Scale >9, \% } & 38.3 & 55.8 & 2.03 (1.35 to 3.07$)$ & 0.001 \\
\hline \multicolumn{2}{|c|}{$<1$ Bowel motion/day, \% } & 38.2 & 47.0 & $1.48(1.01,2.17) \ddagger$ & $0.043 \ddagger$ \\
\hline QUIP, \% & $\begin{array}{l}\text { Gambling } \\
\text { Sex } \\
\text { Buying } \\
\text { Eating } \\
\text { Hobbyism } \\
\text { Punding } \\
\text { Walkabout } \\
\text { Medication use }\end{array}$ & $\begin{array}{r}1.7 \\
2.9 \\
3.7 \\
5.3 \\
11.7 \\
3.7 \\
0.8 \\
2.1\end{array}$ & $\begin{array}{r}1.4 \\
5.9 \\
6.5 \\
8.1 \\
15.3 \\
8.1 \\
1.4 \\
2.7\end{array}$ & $\begin{array}{l}0.84 \text { (0.19 to } 3.63) \\
1.90 \text { (0.71 to } 5.05) \\
1.58(0.64 \text { to } 3.90) \\
1.63(0.76 \text { to } 3.50) \\
1.26(0.71 \text { to } 2.22) \\
2.27(0.98 \text { to } 5.27) \\
1.48 \text { (0.24 to } 9.14) \\
1.32 \text { (0.38 to } 4.55)\end{array}$ & $\begin{array}{l}0.8 \\
0.2 \\
0.3 \\
0.2 \\
0.4 \\
0.05 \\
0.7 \\
0.7\end{array}$ \\
\hline UPDRS I, \% & $\begin{array}{l}\text { Cognitive impairment } \\
\text { Hallucinations } \\
\text { Depressed mood } \\
\text { Anxious mood } \\
\text { Apathy } \\
\text { Features of DDS } \\
\text { Sleep problems } \\
\text { Daytime sleepiness } \\
\text { Pain } \\
\text { Urinary problems } \\
\text { Constipation } \\
\text { Light headedness on standing } \\
\text { Fatigue }\end{array}$ & $\begin{array}{r}30.8 \\
8.8 \\
16.4 \\
27.9 \\
13.5 \\
2.4 \\
63.2 \\
77.5 \\
76.8 \\
59.6 \\
40.7 \\
35.7 \\
69.5\end{array}$ & $\begin{array}{r}47.3 \\
19.2 \\
26.8 \\
35.3 \\
22.8 \\
5.8 \\
82.3 \\
84.5 \\
85.0 \\
70.0 \\
58.8 \\
52.5 \\
76.5\end{array}$ & $\begin{array}{l}1.93(1.33 \text { to } 2.81) \\
2.39(1.35 \text { to } 4.21) \\
1.99(1.27 \text { to } 3.13) \\
1.51(1.02 \text { to } 2.23) \\
1.93(1.19 \text { to } 3.16) \\
2.46(0.91 \text { to } 6.68) \\
2.72(1.77,4.18) \\
1.57(0.96 \text { to } 2.56) \\
1.77(1.08 \text { to } 2.89) \\
1.65(1.11 \text { to } 2.44) \\
2.10(1.44 \text { to } 3.04) \\
1.97(1.36 \text { to } 2.86) \\
1.40 \text { (0.93 to } 2.12)\end{array}$ & $\begin{array}{l}0.001 \\
0.002 \\
0.003 \\
0.05 \\
0.008 \\
0.08 \\
<0.001 \\
0.07 \\
0.02 \\
0.01 \\
<0.001 \\
<0.001 \\
0.1\end{array}$ \\
\hline
\end{tabular}

association. Our findings would support the theory that the presence of RBD in PD is representative of a more diffuse disease process early in its evolution, perhaps explained by the proximity of the serotoninergic raphe and other brainstem nuclei to the nuclei implemented in the pathophysiology of RBD. $^{3}$
Previous studies have reported an increased prevalence of mild cognitive impairment (MCI) in patients with RBD and more established PD. ${ }^{37} 38$ Here, for the first time, we have shown a significant difference in the cognitive scores of patients with early PD, with and without concomitant pRBD. While the difference in the total MMSE score was modest and could be

Table 4 The impact of health on the activities of daily living in subjects with Parkinson's disease (PD-non-RBD) and Parkinson's disease and probable REM sleep behaviour disorder (PD-RBD)

\begin{tabular}{|c|c|c|c|c|c|}
\hline & & PD-non-RBD (n=251) & PD-RBD (n=224) & $\begin{array}{l}\text { Adjusted difference in means* } \\
\text { (PD-RBD-PD-non-RBD) }(95 \% \mathrm{Cl})\end{array}$ & p Value* \\
\hline \multirow[t]{8}{*}{ EQ-5D } & Continuous measures & & & & \\
\hline & Patient-reported health score & $71.9 \pm 16.9$ & $66.4 \pm 19.6$ & $-5.05(-8.32$ to -1.78$)$ & 0.003 \\
\hline & Binary measures & & & Adjusted OR* $(95 \% \mathrm{Cl})$ & \\
\hline & Problems with mobility, \% & 44.2 & 54.3 & 1.46 (1.01 to 2.12$)$ & 0.04 \\
\hline & Problems with self-care, \% & 18.4 & 27.8 & 1.72 (1.11 to 2.64$)$ & 0.02 \\
\hline & Problems with activities, \% & 39.8 & 53.2 & 1.68 (1.16 to 2.44$)$ & 0.006 \\
\hline & Problems with pain, \% & 55.8 & 64.9 & $1.52(1.03$ to 2.25$)$ & 0.03 \\
\hline & Problems with anxiety and depression, $\%$ & 33.5 & 51.6 & 2.16 (1.49 to 3.13$)$ & $<0.001$ \\
\hline
\end{tabular}

${ }^{*}$ Adjusted for age, sex, disease duration and smoking history. 
Table 5 The prevalence of REM sleep behaviour disorder (RBD) in patients with Parkinson's disease (PD)

\begin{tabular}{|c|c|c|c|c|}
\hline Study & Number participants with PD & Mean disease duration in years (SD) & Method of RBD diagnosis & $\begin{array}{l}\text { Percentage of patents with } \\
\text { concomitant RBD }(95 \% \mathrm{Cl})\end{array}$ \\
\hline Our study & 475 & $1.5(1)$ & Questionnaire & 47.2 (42.7 to 51.9$)$ \\
\hline De Cock, $2007^{22}$ & 100 & $7(4)$ & PSG & $41.0(31.4$ to 50.6$)$ \\
\hline Postuma, $2008^{28}$ & 36 & $7.7(6.2)$ & PSG & 58.3 (42.2 to 74.4$)$ \\
\hline Vibha, $2011^{23}$ & 134 & $5.5(4.1)$ & Questionnaire & 19.4 (12.7 to 26.4$)$ \\
\hline Gjerstad, $2008^{25}$ & 231 & $9.0(5.6)$ & Questionnaire & $14.7(10.1$ to 19.3$)$ \\
\hline Scaglione, $2005^{27}$ & 195 & $8.1(5.1)$ & Questionnaire & 32.8 (26.2 to 39.4$)$ \\
\hline Lavault, $2010^{8}$ & 61 & $6.9(4.7)$ & Questionnaire & 63.4 (51.3 to 75.5$)$ \\
\hline Lee, $2010^{29}$ & 447 & $6.1(4.6)$ & Questionnaire & 36.7 (32.2 to 41.7$)$ \\
\hline Pacchetti, $2005^{30}$ & 289 & $8.4(5.4)$ & Questionnaire & 26.6 (21.5 to 31.7$)$ \\
\hline Yoritaka, $2009^{31}$ & 150 & $6.4(4.6)$ & Questionnaire & $54.0(46.0$ to 62.0$)$ \\
\hline Chahine, $2013^{14}$ & 75 & $4.0(4.0)$ & PSG & 41.3 (30.2 to 52.4$)$ \\
\hline Bugalho, $2010^{32}$ & 75 & $2.8(1.4)$ & Questionnaire & $54.6(43.3$ to 65.9$)$ \\
\hline Poryazova, $2013^{33}$ & 417 & $11(7)$ & Questionnaire & 41.2 (36.5 to 45.9$)$ \\
\hline
\end{tabular}

PSG, polysomnography.

the result of multiple comparisons $(p=0.03)$, the difference in the number of subjects in each group satisfying the screening criteria for cognitive impairment was much higher in the PD-RBD group (14.9\% vs $56.7 \%$; $=0.006$ ) (figure 1 ).

Collectively, we have shown that pRBD was associated with worse non-motor symptom severity scores, a higher prevalence of mood disorders, daytime sleepiness and cognitive impairment, and a greater impact on activities of daily living. By replicating the results after excluding patients with possible RBD secondary to medication use, we have shown that the observed differences were likely to be due to the underlying pathology. These findings go some way to support previous theories that RBD marks a more diffuse and complex phenotype of PD. ${ }^{39}$ However, we cannot specify whether it is the pRBD itself that is responsible for this phenotype or whether this is due to an association with other non-motor symptoms, for example, a greater prevalence of depression or cognitive impairment.

A clear limitation of our study is that the diagnosis of RBD was based on a questionnaire and not confirmed by objectively PSG.

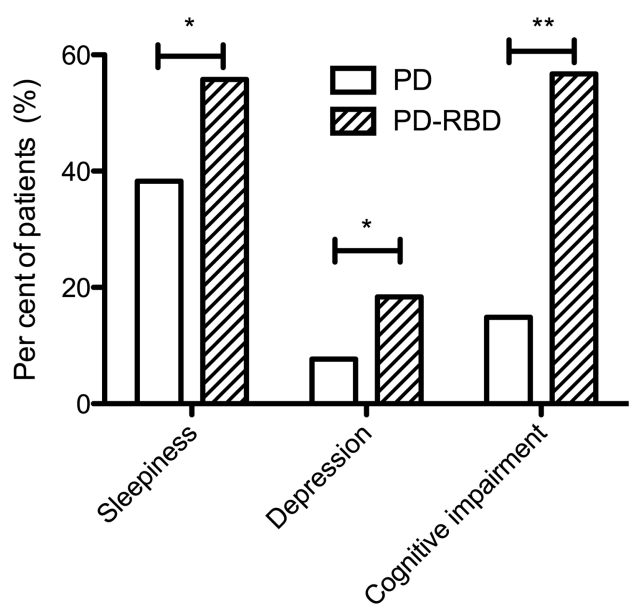

Figure 1 The frequency of clinically significant scores on disease severity scales. Sleepiness defined as Epworth Sleepiness Scale $>9$; Depression defined as Beck Depression Inventory $>16$; Cognitive impairments defined as MMSE score $<26$. ${ }^{*} \mathrm{p}=0.001$, ${ }^{*} \mathrm{p}=0.006$; all scores adjusted for age, sex, disease duration and smoking history.
While PSG inevitably remains the gold standard, studies have supported the use of RBDSQ in screening for $\mathrm{pRBD}^{40}$ and its role in clinical studies. Importantly, it must also be noted that while the RBDSQ does not require the input from a bed partner, thus making it ideal for screening large populations where this information may not be available, this may lead to the underdiagnosis of pRBD. A further limitation of this study is the use of screening questionnaires for conditions such as depression, excessive sleepiness and cognitive impairment. Although these questionnaires can give an insight into the prevalence certain patient-reported symptoms, further information and assessment is required to allow a clinical diagnosis to be made.

\section{CONCLUSIONS}

Findings from early PD in the Discovery cohort confirm that $\mathrm{RBD}$ is common throughout its natural history, consistent with neuropathological staging. Patients with early PD and concomitant $\mathrm{pRBD}$ have a different phenotype with greater prevalence of some non-motor features. At this stage, we cannot speculate on their rate of motor progression compared to non-pRBD patients. Further follow-up will enable us to explore whether pRBD should be routinely collected as a potential biomarker for clinical progression in PD.

Acknowledgements The authors would like to thank Dr Clare E. Mackay, the editors and the anonymous reviewers for their useful comments, and all patients who have participated in this study.

Contributors MR: research project conception, organisation and execution, statistical analysis and manuscript preparation. KS-K, PT, KN: research project organisation and execution, manuscript review and critique. KT: research project conception, manuscript review and critique. YB-S: research project conception and organisation, statistical analysis, manuscript review and critique. $\mathrm{MH}$ : research project conception and organisation, manuscript review and critique.

Funding This study was funded by the Monument Trust Discovery Award from Parkinson's UK and supported by the National Institute for Health Research (NIHR) Oxford Biomedical Research Centre based at Oxford University Hospitals NHS Trust and University of Oxford and the Dementias and Neurodegenerative Diseases Research Network (DeNDRoN). The views expressed are those of the author(s) and not necessarily those of the NHS, the NIHR or the Department of Health.

Competing interests None.

Ethics approval Local NHS ethics committee.

Provenance and peer review Not commissioned; externally peer reviewed.

Data sharing statement All data available have been included either in the manuscript or in the Web only files. 
Open Access This is an Open Access article distributed in accordance with the Creative Commons Attribution Non Commercial (CC BY-NC 3.0) license, which permits others to distribute, remix, adapt, build upon this work non-commercially, and license their derivative works on different terms, provided the original work is properly cited and the use is non-commercial. See: http://creativecommons.org/ licenses/by-nc/3.0/

\section{REFERENCES}

1 Schenck $\mathrm{CH}$, Bundlie SR, Ettinger MG, et al. Chronic behavioral disorders of human REM sleep: a new category of parasomnia. Sleep 1986;9:293-308.

2 Boeve BF. REMsleep behavior disorder: Updated review of the core features, the REM sleep behavior disorder-neurodegenerative disease association, evolving concepts, controversies, and future directions. Ann N Y Acad Sci 2010;1184:15-54

3 Boeve BF, Silber MH, Saper CB, et al. Pathophysiology of REM sleep behaviour disorder and relevance to neurodegenerative disease. Brain 2007:130:2770-88.

4 Iranzo A, Molinuevo JL, Santamaria J, et al. Rapid-eye-movement sleep behaviour disorder as an early marker for a neurodegenerative disorder: a descriptive study. Lancet Neurol 2006:5:572-7.

5 Postuma RB, Gagnon JF, Vendette M, et al. Quantifying the risk of neurodegenerative disease in idiopathic REM sleep behavior disorder. Neurology 2009; 72:1296-300.

6 Schenck $\mathrm{CH}$, Bundlie SR, Mahowald MW. Delayed emergence of a parkinsonian disorder in $38 \%$ of 29 older men initially diagnosed with idiopathic rapid eye movement sleep behaviour disorder. Neurology 1996:46:388-93.

7 Schenck $\mathrm{CH}$, Boeve BF, Mahowald MW. Delayed emergence of a parkinsonian disorder or dementia in $81 \%$ of older men initially diagnosed with idiopathic rapid eye movement sleep behavior disorder: a 16-year update on a previously reported series. Sleep Med 2013;14:744-8.

8 Lavault S, Leu-Semenescu S, Tezenas du Montcel S, et al. Does clinical rapid eye movement behavior disorder predict worse outcomes in Parkinson's disease? J Neurol 2010;257:1154-9.

9 Arnulf I. REM sleep behavior disorder: motor manifestations and pathophysiology. Mov Disord 2012;27:677-89.

10 Braak H, Del Tredici K, Rüb U, et al. Staging of brain pathology related to sporadic Parkinson's disease. Neurobiol Aging 2003:24:197-211.

11 Hughes AJ, Jennum P, Daniel SE, et al. Accuracy of clinical diagnosis of idiopathic Parkinson's disease: a clinico-pathological study of 100 cases. J Neurol Neurosurg Psychiatr 1992;55:181-4.

12 Stiasny-Kolster K, Mayer G, Schäfer S, et al. The REM sleep behavior disorder screening questionnaire-a new diagnostic instrument. Mov Disord 2007;22:2386-93.

13 Nomura T, Inoue Y, Kagimura T, et al. Utility of the REM sleep behavior disorder screening questionnaire (RBDSQ) in Parkinson's disease patients. Sleep Med 2011;12:711-3.

14 Chahine LM, Daley J, Horn S, et al. Questionnaire-based diagnosis of REM sleep behavior disorder in Parkinson's disease. Mov Disord 2013;28:1146-9.

15 Nomura T, Iranzo A, Inoue $Y$, et al. Bisoprolol-induced rapid eye movement sleep behavior disorder. Am J Med 1999;107:390-2.

16 Goetz CG, Tilley BC, Shaftman SR. Movement Disorder Society-sponsored revision of the Unified Parkinson's Disease Rating Scale (MDS-UPDRS): scale presentation and clinimetric testing results. Mov Disord 2008;23:2129-70.

17 Sixel-Döring F, Trautmann E, Mollenhauer B, et al. Associated factors for REM sleep behavior disorder in Parkinson disease. Neurology 2011;77:1048-54.

18 Dalrymple-Alford JC, MacAskill MR, Nakas CT, et al. The MoCA: well-suited screen for cognitive impairment in Parkinson disease. Neurology 2010;75:1717-25.

19 Beck AT, Steer RA, Ball R, et al. Comparison of Beck Depression Inventories-IA and-II in Psychiatric Outpatients. Journal of Personality Assessment 1996;67:588-97.
20 Weintraub D, Weintraub D, Hoops $S$, et al. Validation of the questionnaire for impulsive-compulsive disorders in Parkinson's disease. Mov Disord 2009;24:1461-7.

21 The EuroQol Group. EuroQol-a new facility for the measurement of health-related quality of life. Health Policy 1990;16:199-208.

22 De Cock VC, Vidailhet M, Leu S, et al. Restoration of normal motor control in Parkinson's disease during REM sleep. Brain 2007;130:450-6.

23 Vibha D, Shukla G, Goyal V, et al. RBD in Parkinson's disease: a clinical case control study from North India. Clin Neurol Neurosurg 2011;113:472-6.

24 Postuma RB, Gagnon JF, Vendette M, et al. REM sleep behaviour disorder in Parkinson's disease is associated with specific motor features. J Neurol Neurosurg Psychiatr 2008;79:1117-21.

25 Gjerstad MD, Boeve B, Wentzel-Larsen T, et al. Occurrence and clinical correlates of REM sleep behaviour disorder in patients with Parkinson's disease over time. J Neurol Neurosurg Psychiatr 2008;79:387-91.

26 Sixel-Döring F, Schweitzer M, Mollenhauer B, et al. Intraindividual variability of REM sleep behavior disorder in Parkinson's disease: a comparative assessment using a new REM sleep behavior disorder severity scale (RBDSS) for clinical routine. I Clin Sleep Med 2011:7:75-80.

27 Scaglione C, Vignatelli L, Plazzi G, et al. REM sleep behaviour disorder in Parkinson's disease: a questionnaire-based study. Neurol Sci 2005;25:316-21.

28 Postuma RB, Gagnon J-F, Vendette $M$, et al. Manifestations of Parkinson disease differ in association with REM sleep behavior disorder. Mov Disord 2008;23:1665-72.

29 Lee JE, Kim KS, Shin H-W, et al. Factors related to clinically probable REM sleep behavior disorder in Parkinson disease. Parkinsonism Relat Disord 2010;16:105-8.

30 Pacchetti C, Manni R, Zangaglia R, et al. Relationship between hallucinations, delusions, and rapid eye movement sleep behavior disorder in Parkinson's disease. Mov Disord 2005:20:1439-48.

31 Yoritaka A, Ohizumi H, Tanaka S, et al. Parkinson's disease with and without REM sleep behaviour disorder: are there any clinical differences? Eur Neurol 2009;61:164-70.

32 Bugalho P, da Silva JA, Neto B. Clinical features associated with REM sleep behavior disorder symptoms in the early stages of Parkinson's disease. J Neurol 2011;258:50-5.

33 Poryazova R, Oberholzer M, Baumann CR, et al. REM Sleep Behavior Disorder in Parkinson's Disease: A Questionnaire-Based Survey. J Clin Sleep Med 2013;9: 55-9.

34 Kumru H, Santamaria J, Tolosa E, et al. Relation between subtype of Parkinson's disease and REM sleep behavior disorder. Sleep Med 2007:8:779-83.

35 Goetz CG, Ouyang B, Negron A, et al. Hallucinations and sleep disorders in PD: ten-year prospective longitudinal study. Neurology 2010;75:1773-9.

36 Postuma RB, Gagnon JF, Vendette M, et al. Markers of neurodegeneration in idiopathic rapid eye movement sleep behaviour disorder and Parkinson's disease. Brain 2009;132:3298-307.

37 Sinforiani E, Zangaglia R, Manni R, et al. REM sleep behavior disorder, hallucinations, and cognitive impairment in Parkinson's disease. Mov Disord 2006;21:462-6.

38 Gagnon J-F, Vendette M, Postuma RB, et al. Mild cognitive impairment in rapid eye movement sleep behavior disorder and Parkinson's disease. Ann Neurol 2009;66:39-47.

39 Postuma RB, Bertrand J-A, Montplaisir J, et al. Rapid eye movement sleep behavior disorder and risk of dementia in Parkinson's disease: a prospective study. Mov Disord 2012;27:720-6.

40 Nomura T, Inoue $Y$, Kagimura $T$, et al. Clinical significance of REM sleep behavior disorder in Parkinson's disease. Sleep Med 2013;14:131-5. 